\title{
The interaction of syntactic change and information status effects in the change from OV to VO in English*
}

\author{
Ann Taylor \\ Susan Pintzuk \\ University of York. Department of Language and Linguistic Science \\ ann.taylor@york.ac.uk \\ susan.pintzuk@york.ac.uk
}

Received: December 192010

Accepted: May 102011

\begin{abstract}
It is well known that the position of constituents in a clause is influenced by information structure: the cross-linguistic generalization is that given information frequently comes early in the clause and new information is placed towards the end. In this article we investigate the relation between syntactic change and information status on alternations in Old English and Early Middle English verb-object order, OV vs. VO. Our main hypothesis is that syntactic change and the constraints of information status are independent. The analysis we present is based on 1500 AuxV and VAux clauses from seven Old English texts and three Middle English texts. We consider three independent variables that influence the position of objects within the clause: text, information status and syntactic complexity. We build a quantitative model with syntactic change over time proceeding independently of synchronic syntactic variation due to information status and syntactic complexity; we then test the model against the Old and Middle English data and also against Icelandic historical data exhibiting the same types of variation. We show that the patterns predicted by our model show up clearly in both English and Icelandic, strongly confirming our hypotheses.
\end{abstract}

Keywords: Old English; Icelandic; information structure/status; syntactic change; quantitative models.

\section{Table of Contents}

\section{Introduction}

2. Background: the variable constituent order of OE and EME clauses

3. Data and Methodology 4. Syntactic Change in OE and EME
5. Testing the models

6. Older Icelandic

7. Conclusions

References

* Some of the data and concepts in this paper have been presented at the International Conference on English Historical Linguistics 15 (Munich 2008); New Ways of Analyzing Variation 9 (Ottawa 2009), Studies in the History of the English Language 6 (Banff 2009); and the Information Structure and Word Order Change in Germanic and Romance Languages Workshop (Oslo 2011). We thank audiences at these talks for helpful comments and discussion. All errors and omissions remain our own responsibility. 


\section{Introduction}

It is well-known that the position of constituents in the clause may be influenced by information structure. If we define 'given' information as that known by or accessible to the hearer, and 'new' information as that not known and not accessible, the cross-linguistic generalization is that given information frequently comes early in the clause and new information is placed towards the end (see, for instance, the 'Given Before New Principle' of Gundel 1988). In languages such as Present-Day English (PDE), the position of arguments is largely fixed; there is little scope for information structure to influence the position of particular arguments in basic SVO sentences. Nevertheless, we still see the general ordering pattern: subjects commonly contain given information, while new information is more likely to be introduced in the VP, e.g. by the object or by the entire VP (Prince 1981). In cases where there is scope for variation, e.g. in clauses with more than one complement and/or adjunct, processes such as dative alternation and heavy-NP shift may apply to produce alternative orders, with the information status of the constituents clearly relevant to the ordering (see Arnold et al. 2000, Wasow and Arnold 2003 and references therein).

In contrast, in Old English (OE) the position of objects is much freer than in PDE; therefore we might expect a tighter correlation between information status and object position in a wider range of OE clauses. Although early studies of $\mathrm{OE}$ have looked at information structure as an effect on word order, most of these present qualitative rather than quantitative results. Noted exceptions are Bech 2001 and Kohonen 1978 (cf. also Taylor \& Pintzuk 2009, 2010, to appear). Kohonen investigates the position of subjects, objects and adverbials in one OE and two Early Middle English (EME) texts. His results are somewhat difficult to interpret in detail, since he collapses categories such as pronominal phrases, full nominal phrases and relativizers. Nevertheless, his overall conclusion is clear: «The study of givenness showed that there was a general tendency to arrange constituents in a given-new perspective. This was evident in a comparison of positional tendencies of elements rated as given and new: given elements could occur in all positions [AT/SP: initial (topic) field, medial field (pre-verbal) and terminal field (postverbal)], while new elements had a clear preference for the medial and terminal fields.» (Kohonen 1978:191). Likewise Bech 2001 investigates the interaction of syntax and pragmatic factors in Old and Middle English and concludes that the OE verb-second (V2) constraint can be overridden in some clause types by the demands of 'information value', which is correlated with given/new information status.

In this article we investigate the relation between syntactic change and information status on alternations in OE and EME verb-object order, OV vs. VO. Our main hypothesis is that syntactic change and the constraints of information status are independent. The article is organized as follows: Section 2 presents background information on constituent order in OE. Section 3 discusses the data and methodology used in our investigation. Section 4 outlines the syntactic and quantitative models underlying our analysis, and we propose three specific hypotheses about the $\mathrm{OV} / \mathrm{VO}$ variation in OE and EME. In Section 5 we test the models using data from 
ten $\mathrm{OE}$ and EME texts. Section 6 contrasts our analysis with an analysis recently proposed for Older Icelandic. Section 7 presents conclusions.

\section{Background: the variable constituent order of OE and EME clauses}

Studies of syntactic change necessarily involve the study of syntactic variation: it is clear from the historical record that all change includes a period of variation between the conservative and innovative variants. In the history of English, variation between object-verb (OV) and verb-object (VO) order appeared in written texts for several hundred years, with the frequency of VO gradually increasing over time until OV was finally lost in Early Modern English. Variation and change in the position of the object is one of the best-studied phenomena in the history of English, and it has been the focus of much research in the past two decades (see, for example, Taylor \& van der Wurff 2005, and the references cited there).

Variation between $\mathrm{OV}$ and $\mathrm{VO}$ is not the only type of long-term variation in constituent order exhibited by OE and EME: the non-finite main verb (V) can appear either before or after the finite auxiliary (Aux). Main clauses show a preference for the verb in second position and the object after the verb, while subordinate clauses favour the finite verb in final position, with the object before verb; but variation exists in all clause types. Examples are given in (1) and (2). Auxiliaries are underlined, main verbs are italicized and objects are in bold face.

(1) main clauses

a. Aux O V

Martianus hæfde his sunu ær befast

Martin had his son earlier established

'Martin had earlier established his son.'

(coaelive,+ALS_[Julian_and_Basilissa]: 184.1049)

b. Aux V O

Se wolde gelytlian pone lyfigendan hælend

He would diminish the living saviour

'He would diminish the living saviour.'

(colwstan1,+ALet_2_[Wulfstan_1]: 55.98)

c. O V Aux

and hi heore diglan dæda eow bedyrnan ne mihton

and they their secret deeds (from) you hide NEG could

'and they could not hide their secret deeds from you.'

(coaelive,+ALS_[Vincent]: 137.7882)

d. V Aux O

he pæs habban sceal ece edlean on Godes rice

he of-that have must eternal reward in God's kingdom

'he must have eternal reward of that in God's kingdom.'

(cowulf,WHom_7: 161.501) 
(2) subordinate clauses

a. Aux O V

purh pa heo sceal hyre scippend understandan

through which it must its creator understand

'through which it must understand its creator.'

(coaelive,+ALS_[Christmas]: 157.125)

b. Aux V O

swa pæt heo bið forloren pam ecan life

so that it is lost (to) the eternal life

'so that it is lost to the eternal life.'

(coaelive,+ALS_[Christmas]: 144.117)

c. O V Aux

gif heo pæt bysmor forberan wolde

if she that disgrace tolerate would

'if she would tolerate that disgrace.'

(coaelive,+ALS_[Eugenia]: 185.305)

d. V Aux O

pæt he friðian wolde pa leasan wudewan

that he make-peace-with would the false widow

'that he would make peace with the false widow.'

(coaelive,+ALS_[Eugenia]: 209.315)

\section{Data and Methodology}

As is usual in this type of study, we limit the data to clauses with a finite auxiliary verb and a nonfinite main verb in order to abstract away from the effects of V2 (Kroch \& Taylor 2000a, Pintzuk 1999, Pintzuk \& Taylor 2006). While this focus on clauses with two verbs minimizes structural ambiguity, it increases the types of variation as shown above, since the verbs can also appear in two orders: combining the OV/VO and the AuxV/VAux alternations, we have four variants in the data: Aux-V-O, Aux-O-V, O-V-Aux and V-Aux-O. ${ }^{1}$

The analysis we present is based on data from seven OE texts ${ }^{2}$ (Orosius, Boethius, Cura Pastoralis, Catholic Homilies I, Catholic Homilies II, Lives of Saints, Gregory's Dialogues (C)) and three ME texts (Trinity Homilies, Katherine Group, ${ }^{3}$ Ancrene Riwle), taken from two syntactically annotated corpora: the York-

1. We ignore two logical possibilities: 1) V-O-Aux clauses, since they do not exist (Biberauer et al. 2008, Biberauer et al. 2009, Pintzuk 2005); and 2) O-Aux-V clauses, since the constraints on objects in pre-Aux position may be different from those in post-Aux position; these objects will be investigated in future work.

2. We originally included Bede's Ecclesiastic History, but we found the behaviour of objects to be different both qualitatively and quantitatively from the other OE texts.

3. Five texts are included in this group: Sawles Warde, Hali Meidhad, St. Katherine, St. Juliana, St. Margaret. See Kroch and Taylor 2000a:136 for justification for grouping these texts together. 
Toronto-Helsinki Parsed Corpus of Old English Prose (YCOE, Taylor et al. 2003) and the Penn-Helsinki Parsed Corpus of Middle English (PPCME2, Kroch and Taylor 2000b). We collected an exhaustive sample of clauses with VAux order and objects (either pre- or post-verbal) from all ten texts. Our AuxV sample is exhaustive for Orosius, Boethius, Trinity Homilies, Katherine Group and Ancrene Riwle, contains about two-thirds of the relevant tokens from Catholic Homilies I, and about one-third of the relevant tokens from Cura Pastoralis, Catholic Homilies I, Catholic Homilies II, Lives of Saints, Gregory's Dialogues (C). We excluded the following types of data:

- VAux main clauses with non-overt subjects, or with the object before the subject, to avoid potential cases of topicalization, as in (3);

- pronominal (personal and demonstrative) objects, since pronominal objects usually appear preverbally, particularly in VAux clauses (Pintzuk 2005);

- quantified objects (including negative objects), for two reasons: first, it is difficult to determine their information status; second, it has been shown (Pintzuk and Taylor 2006) that quantified objects exhibit special syntactic behaviour;

- objects containing a clause, such as a relative clause, etc., since clausal objects almost invariably appear post-verbally;

- a few additional cases where the information status of the object is unclear.

(3) O S V Aux

and pam deadan pu ne miht eft lif forgifan

and (to) the dead you NEG can again life give

'and you cannot give life again to the dead.'

(coaelive,+ALS_[Cecilia]: 327.7304)

We consider three independent variables that influence the position of objects within the clause: text, information status and syntactic complexity. ${ }^{4}$ For the assignment of information status to entities within utterances, we have used a binary distinction, in line with other similar studies, e.g. new vs. given/inferable for Arnold et al. 2000, high information value vs. low information value for Bech 2001). However, defining these notions on the basis of discourse mention alone is clearly inadequate, since an entity does not have to be mentioned in order to be accessible to or identifiable by the hearer. We therefore divide the data into given and new entities primarily on the basis of insights drawn from the work of Birner (2006) (building on Prince (1981)) and Gundel et al. (1993). Our new category includes referentially new objects, new discourse referents (in the sense of Karttunen 1976) and «bridging» inferables (in the sense of Birner 2006). All other entities (previously mentioned, shared/cultural knowledge, situationally evoked, «elaborating» inferables (Birner 2006) and semantically incorporated) are considered accessible

4. Text was coded automatically by CorpusSearch 2 , the search engine used for corpora annotated like the YCOE and the PPCME2; information status and syntactic complexity were coded manually. 
to the hearer and are coded as given. In the examples below, the coded object is in bold, and the prior or subsequent reference, if it exists, is underlined.

(4) referentially new

Be ðam sagað Sanctus Arculfus

about that said Saint Arculfus

pæt he gesawe medmicle cirican butan Bethlem pære ceastre

that he saw little church outside Bethlehem the city

'St. Arculfus says about this that he saw a little church outside the city of Bethlehem.'

(Mart_5_[Kotzor].Se30_A.3.1906)

(5) new discourse referent: a short-term discourse referent that is referred to later in the discourse with a definite expression (usually a pronoun), but the referent is not a specific entity

Đeah pe hwa wille her on life habban gode dagas, he ne mæg Yet whoever will here in life have good days, he NEG can hi her findan

them here find

'Yet whoever will have good days here in life, he cannot find them here.'

(coaelive,+ALS[Ash_Wed]: 82.2748)

(6) bridging inferable: the referent is anchored to an already mentioned referent but the referent is not accessible without the anchor (frequently cases of alienable possession)

ðæt is, ðæt ic sette minne renbogan on wolcnum

that is, that I set my rainbow in clouds

'that is, that I set my rainbow in the clouds.'

(cootest,Gen.9.13.388)

(7) previously mentioned

$\&$ of $\underline{\text { ðæs treowes }}$ wæstme pe is on middan neorxnawange,

and of the tree's fruit which is in middle paradise

God bebead us, ðæt we ne æton, ne we ðæt treow ne hrepodon

God bid us that we NEG eat nor we the tree NEG touched

ði læs ðe we swelton.

lest we die

'and of the fruit of the tree which is in the middle of Paradise, God bid us that we may not eat, nor may we touch the tree lest we die.'

(cootest,Gen:3.3.123)

(8) shared/cultural knowledge

Ond peah pe wærgcweodole Godes rice gesittan ne mægen

And although those-that-curse God's kingdom occupy NEG may

'And although those that curse may not occupy God's kingdom ...'

(cobede,Bede_4:27.356.26.3595) 
(9) situationally evoked: the referent forms part of the situation of the discourse, and is therefore 'known' to both the speaker and the hearer

[Context: Katherine has been matched against fifty debaters.]

PV qð ha keiser nauest nawt pis strif rihtwisliche idealet

You said she Emperor NEG-have not this contest fairly matched

'Emperor, she said, you have not matched this contest fairly...'

(CMKATHE,30.187)

(10) elaborating inferable: the referent is anchored to an already mentioned referent and the referent is accessible without the anchor (frequently body parts or other cases of inalienable possession)

Healdað mine bebodu \& mine domas

Keep my commands and my judgements

ðæt ge libbon eower lif butan ælcere sorhge.

so-that you may-live your life without any sorrow

'Keep my commands and my judgements so you may live your life without any sorrow.'

(Lev:25.18.3864)

(11) semantically incorporated: predicate conflation in the sense of Du Bois 1980:214, where a nominal is used together with a verb to express a unitary concept

pæt hi moston wite prowian for criste

that they might torture suffer for Christ

'that they might suffer torture (i.e. 'be tortured') for Christ.'

(coaelive,+ALS_[Chrysanthus]:216.7456)

To code syntactic complexity, we distinguish simple objects from complex objects. Simple objects are those that are unmodified, or pre-modified (e.g. by an adjective/adjectival phrase) or modified by a pre- or post-nominal genitive; complex objects are those that are conjoined or are post-modified by anything except a genitive (e.g. adjective/adjectival phrase, prepositional phrase, appositive, etc.). ${ }^{5}$ Bies 1996, Gries 2003, Taylor and Pintzuk (to appear), Wasow 2002, among others, have demonstrated that complexity has a significant effect on the position of constituents, and that this effect is independent from the effects of both weight and information status; we therefore limited our data to simple objects as defined above.

After exclusions, our dataset contains 1507 clauses. Table 1 gives the basic statistics for the total dataset, by text, verb order (AuxV vs. VAux) and position of object (OV vs. VO): 6

5. We originally separated objects with post-nominal genitives from the other types of modified objects, since we didn't know whether they would pattern with objects with post-nominal modifiers or with objects with pre-nominal genitives. In our data, objects with post-nominal genitives behave like the other simple objects in showing length effects; complex objects, in contrast, do not show length effects.

6. Percentages calculated from less than 10 tokens are shown in brackets. 
Table 1. The dataset by text, verb order and position of object

\begin{tabular}{lrrrrrrrrrr}
\hline & \multicolumn{4}{c}{ AuxV clauses } & & \multicolumn{4}{c}{ VAux clauses } \\
\cline { 2 - 3 } Text & OV & vo & Total & \%VO & & OV & & vo & Total & $\%$ VO \\
\hline Orosius & 89 & 21 & 110 & 19.1 & & 71 & 4 & 75 & 5.3 \\
Boethius & 71 & 72 & 143 & 50.3 & & 70 & 5 & 75 & 6.7 \\
Cura Pastoralis & 34 & 28 & 62 & 45.2 & & 44 & 14 & 58 & 24.1 \\
Catholic Homilies I & 108 & 84 & 192 & 43.8 & & 58 & 16 & 74 & 21.6 \\
Catholic Homilies II & 43 & 33 & 76 & 43.4 & & 51 & 9 & 60 & 15.0 \\
Lives of Saints & 42 & 51 & 93 & 54.8 & & 24 & 25 & 49 & 51.0 \\
Gregory's Dialogues (C) & 23 & 34 & 57 & 59.6 & & 28 & 15 & 43 & 34.9 \\
Trinity Homilies & 51 & 46 & 97 & 47.4 & & 0 & 4 & 4 & {$[100.0]$} \\
Katherine Group & 28 & 47 & 75 & 62.7 & & 1 & 3 & 4 & {$[75.0]$} \\
Ancrene Riwle & 42 & 117 & 159 & 73.6 & & 1 & 0 & 1 & {$[0.0]$} \\
\hline Total & 531 & 533 & 1064 & 50.1 & & 348 & 95 & 443 & 21.4 \\
\hline
\end{tabular}

\section{Syntactic Change in OE and EME}

In order to discuss syntactic change in OE and EME in a concrete way, we adopt a particular syntactic model, one that permits projections (IP and VP) to be either head-initial or head-final. ${ }^{7}$ As we will see below, the crucial feature of the model is that it has two post-verbal positions and therefore two derivations for post-verbal objects, one for (narrowly) focussed objects and one for non-focussed objects. Our concern here is not the details of the two derivations but only their existence.

\subsection{The Syntactic Model}

Over the OE and ME periods, two independent but interlocked syntactic changes take place: VAux structure is gradually replaced by AuxV in the IP, and OV structure is replaced by VO in the VP. In VAux clauses, where the VP is necessarily head-final, ${ }^{8}$ as shown in (12), objects can appear in post-verbal position only by movement to a position to the right of Aux, as in (13). ${ }^{9}$

(12) $\left[_{\mathrm{IP}}[\mathrm{VP} \mathrm{O} \mathrm{V}]\right.$ Aux ]

(13) $\left[{ }_{\mathbb{P}}\left[{ }_{\mathrm{PP}}\left[\mathrm{vP}_{\mathrm{i}} \mathrm{V}\right]\right.\right.$ Aux $\left.] \mathrm{O}_{\mathrm{i}}\right]$

7. The analysis works equally well if we assume an anti-symmetry model such as Wallenberg (2009).

8. For reasons that aren't well understood (but cf. Biberauer et al. 2008, 2009, inter alia), a head-final IP cannot dominate a head-initial VP, i.e. the structure $*\left[_{\mathrm{IP}}[\mathrm{VP} V \mathrm{~V}\right.$ ] Aux $]$ is never generated or derived. Thus the change from VAux to AuxV is a necessary precondition for the change from OV to VO.

9. We assume postposed constituents adjoin to the right periphery of IP; nothing crucial rests on this assumption. 
Bies (1996) and Hinterhölzl (2009) demonstrate that this position is associated with narrow focus on the object in earlier stages of German, and we assume that the same is true in OE. As new objects are more likely to be the narrow focus of a clause than given objects, we expect the set of objects in post-verbal position in structure (13) to include a higher frequency of new objects than the set of objects in pre-verbal position in structure (12).

AuxV clauses, on the other hand, are the locus of the change from OV to VO within the VP. Thus Aux-O-V represents the conservative variant with respect to the position of the object, and Aux-V-O the innovative. The object is in its base position in the conservative variant, ${ }^{10} 10$ as shown in (14); the structure of the innovative variant is similar but with a head-initial rather than head-final VP, as in (15):

(14) $\left[_{\mathrm{IP}}\right.$ Aux $\left[{ }_{\mathrm{VP}} \mathrm{O}\right.$ V ] $]$

(15) $\left[{ }_{\mathrm{IP}}\right.$ Aux $\left[{ }_{\mathrm{VP}} \mathrm{V}\right.$ O ] $]$

Here a complication arises: we know from structure (13) that OE has a narrow focus position to the right of VP/IP, and there is no reason to suppose that its existence is dependent on verb order. The structure of an AuxV clause with an underlyingly head-final VP and a narrow focus object is shown in (16). The surface order Aux-V-O is therefore structurally ambiguous, depending on whether the object is in the position for narrow focus, as in structure (16), or not, as in structure (15).

(16) $\left[_{\mathrm{IP}}\left[{ }_{\mathrm{IP}} \operatorname{Aux}\left[{ }_{\mathrm{VP}} \mathrm{t}_{\mathrm{i}} \mathrm{V}\right]\right] \mathrm{O}_{\mathrm{i}}\right]$

Given this analysis, our predictions are the following: since in structure (16) the object is the narrow focus, the information status effect will be reflected in the set of post-verbal objects, i.e. they will include a higher proportion of new objects than in structure (15). By contrast, since the object is not in the narrow focus position but within the VP in structure (15), we do not expect any information status effect at all, i.e. the proportion of new objects is simply the proportion of new objects in the text as a whole. Unfortunately, we cannot usually determine in any particular case of Aux-V-O surface order whether the underlying structure is (15) or (16). Therefore, for the set of all Aux-V-O clauses, we expect the strong effect of information status in structure (16) to be diluted by the lack of an information status effect in structure (15).

10. This is actually only true of non-negative, non-quantified objects. Negative and quantified objects can move leftward from post- to pre-verbal position in OE AuxV clauses (cf. Pintzuk \& Taylor 2006) and for this reason are omitted from this study. 


\subsection{Change over time}

Let us now consider what happens over time. Suppose that we could locate the precise point in time when the change from OV to VO in AuxV clauses begins, i.e. the point when the first VO structures are generated by OE speakers. During the period just before this point, all of the clauses are underlying OV with all postverbal objects in narrow focus, and we thus expect to see the same information status effect in AuxV clauses as we see in VAux clauses (structures (12) and (13)). From this point on, as the change from $\mathrm{OV}$ to $\mathrm{VO}$ structure progresses, there is a gradual decrease in the proportion of AuxV clauses with underlying OV structure, and thus a gradual decrease in the proportion of Aux-V-O clauses with narrow focus objects that have been moved to post-verbal position (structure (16)) and an increase in the proportion of Aux-V-O clauses that have underlying VO structure (structure (15)). For concreteness, we can build a simple model using the following assumptions: a) the AuxV clauses in the language contain equal numbers of given and new objects, i.e. the ratio of given to new objects overall is $50: 50 ;{ }^{11} \mathrm{~b}$ ) given objects do not postpose, ${ }^{12}$ while new objects postpose at a rate of $20 \%$. With these two assumptions we can see how the surface word order changes as the proportion of underlying OV order drops from $100 \%$ to $0 \%$. The columns of Table 2 are calculated as follows:

- Columns 1-3 contain the number of clauses with underlying OV structure. We are starting (column 1, first row) with 100 clauses in total, 50 old and 50 new according to assumption a, and decreasing in steps of 20 down to 0 . As the number of underlying OV clauses drops, we assume that half of the objects continue to be given and half new (columns 2 and 3); therefore the numbers in columns 2 and 3 are half the number in column 1 .

- Columns 4-6 contain the number of clauses with underlying VO structure. Initially we start with 0 clauses, and increase in steps of 20 up to 100 clauses with underlying $\mathrm{VO}$ structure. Again, since the ratio of given to new is 50:50 (assumption a), the numbers in columns 5 and 6 are half the number in column 4.

- Columns 7-9 contain the number of surface Aux-V-O clauses.

- Column 7 contains the number of Aux-V-O clauses with given objects, and this is simply the number of underlying VO clauses with given objects (column 5).

- Column 8 contains the number of Aux-V-O clauses with new objects. This is calculated by adding the number of underlying VO clauses with new objects (column 6) to the number of underlying OV clauses with new objects where the object has postposed: ${ }^{13}$ the number of new postposed objects is calculated

11. This assumption is for mathematical simplicity only; in our data at any rate, given objects are far more frequent than new ones.

12. Again this assumption is for simplicity only; given objects clearly do appear in the post-verbal narrow focus position, as we will show below.

13. In fact, there is no reason to assume that all narrow focus objects start out in underlying pre-verbal position. They could equally well start out in the post-verbal non-focus position and move from there to the post-verbal focus position. This movement is string vacuous, however, and for simplicity we abstract away from this possibility. 
by taking $20 \%$ (the assumed rate of postposition, assumption b) of the number of underlying OV clauses with new objects (column 3).

- Column 9 contains the total number of surface Aux-V-O clauses, calculated by adding columns 7 and 8 .

- Column 10 contains the proportion of new objects in surface Aux-V-O clauses. This is the number of Aux-V-O clauses with new objects (column 8) divided by the total number of Aux-V-O clauses (column 9).

- Column 11 represents the difference between the proportion of new objects in surface Aux-V-O clauses (column 10) and the overall frequency of new objects (pre-verbal and postverbal) in AuxV clauses (50\% by assumption a).

As shown in the first row of Table 2 below, at the point when all AuxV clauses are underlying OV, $100 \%$ of the post-verbal objects are new (column 10), compared to the proportion of new objects in all AuxV clauses in the language, which we have set at $50 \%$. The gap (column 11) between the overall proportion of new objects in AuxV clauses and the proportion in post-verbal position is thus 50. From the model we can see that as the proportion of underlying OV clauses (column 1) falls, the proportion of clauses with new objects in post-verbal position (column 10) rapidly converges with the overall proportion of new objects in the AuxV clauses of the language $(50 \%)$; this convergence is evident from the decreasing size of the gap (column 11) between the two proportions. In other words, the effect of information status becomes more and more diluted by the underlying VO clauses (which are impervious to information status demands); when the frequency of underlying VO structure reaches $100 \%$ (the last row of Table 2), there is no longer any information status effect on the position of the object with respect to the verb, as is the case in PDE.

This model, of course, is an oversimplification of the actual situation, primarily because given objects can also be in narrow focus and move to the post-verbal focus

Table 2. A model of the interaction of syntactic change and information status over time in AuxV clauses, with respect to new objects in the post-verbal field

\begin{tabular}{|c|c|c|c|c|c|c|c|c|c|c|}
\hline \multicolumn{3}{|c|}{$\begin{array}{l}\text { Underlying OV } \\
\text { Structure }\end{array}$} & \multicolumn{3}{|c|}{$\begin{array}{l}\text { Underlying VO } \\
\text { Structure }\end{array}$} & \multicolumn{3}{|c|}{$\begin{array}{c}\text { Surface } \\
\text { Aux-V-O Order }\end{array}$} & \multirow{2}{*}{$\begin{array}{l}\text { Proportion of New } \\
\text { Objects in Surface } \\
\text { Aux-V-O Clauses }\end{array}$} & \multirow[b]{2}{*}{ Gap } \\
\hline total & given & new & total & given & new & given & new & total & & \\
\hline 100 & 50 & 50 & 0 & 0 & 0 & 0 & $0+\left(50^{*} .2\right)=10$ & 10 & $10 / 10=100 \%$ & $100-50=50$ \\
\hline 80 & 40 & 40 & 20 & 10 & 10 & 10 & $10+\left(40^{*} .2\right)=18$ & 28 & $18 / 28=64 \%$ & $64-50=14$ \\
\hline 60 & 30 & 30 & 40 & 20 & 20 & 20 & $20+\left(30^{\star} .2\right)=26$ & 46 & $26 / 46=57 \%$ & $57-50=7$ \\
\hline 40 & 20 & 20 & 60 & 30 & 30 & 30 & $30+\left(20^{\star} .2\right)=34$ & 64 & $34 / 64=53 \%$ & $53-50=3$ \\
\hline 20 & 10 & 10 & 80 & 40 & 40 & 40 & $40+\left(10^{\star} .2\right)=42$ & 82 & $42 / 82=51 \%$ & $51-50=1$ \\
\hline 0 & 0 & 0 & 100 & 50 & 50 & 50 & $50+\left(0^{*} .2\right)=50$ & 100 & $50 / 100=50 \%$ & $50-50=0$ \\
\hline (1) & (2) & (3) & (4) & (5) & (6) & (7) & (8) & (9) & (10) & (11) \\
\hline
\end{tabular}


position; but they do so at a lower rate than new objects. ${ }^{14}$ It is straightforward to extend the model to include this fact, and the general trend is the same whatever values are chosen for the various parameters: in AuxV clauses the gap between the proportion of new objects in post-verbal position and the overall proportion of new objects converges as the proportion of underlying OV clauses decreases.

In contrast, in VAux clauses (Table 3 below), in which all post-verbal objects are in narrow focus, there is no such change over time. Under the same assumptions as above, we expect the proportion of new objects in post-verbal position (column $10)$ and the gap between the post-verbal new proportion and the overall proportion of new objects in VAux clauses (column 11) to remain constant at 100\% and 50\% respectively, exactly matching the first row in Table 2 which represents the point before the change from OV to VO begins. There can be no change over time with respect to the proportion of OV/VO in these clauses: although the number of VAux clauses decreases, the object is always base-generated in pre-verbal position, and all of the objects in post-verbal position are in narrow focus.

We can track the proportion of new pre-verbal objects over time in AuxV and VAux clauses in the same way. Here we make the same two assumptions as for the previous model with respect to the overall ratio of given to new objects (50:50) and the constraints on the postposition of objects (given objects do not postpose, new objects postpose at a rate of $20 \%$ ). The calculations are performed in a similar way as for Tables 2 and 3. Taking AuxV clauses first, at the time just before the change from $\mathrm{OV}$ to $\mathrm{VO}$ begins (the first row of Table 4), all clauses are again underlying OV (columns 1-3 and 4-6) and all post-verbal objects in narrow focus. To calculate the number of surface OV new objects, we need to subtract the $20 \%$ of new objects in narrow focus that postpose ( $20 \%$ of column 3 ) from the number of base-generated new objects in pre-verbal position (column 3 ). This number, added to the number of given pre-verbal objects (column 7 from column 2), gives the total number of preverbal objects in AuxV clauses (column 9). The proportion of new objects in the pre-verbal field of the surface string (column 10, 44\%) is less than the proportion of new objects in the language (50\%), since some of the originally pre-verbal new objects have postposed. The gap between these two proportions is therefore a negative one (column 11). In contrast to the model for post-verbal new objects, as the

Table 3. A model of the interaction of syntactic change and information status over time in VAux clauses, with respect to new objects in the post-verbal field

\begin{tabular}{|c|c|c|c|c|c|c|c|c|c|c|}
\hline \multicolumn{3}{|c|}{$\begin{array}{l}\text { Underlying OV } \\
\text { Structure }\end{array}$} & \multicolumn{3}{|c|}{$\begin{array}{l}\text { Underlying VO } \\
\text { Structure }\end{array}$} & \multicolumn{3}{|c|}{$\begin{array}{c}\text { Surface } \\
\text { Aux-V-O Order }\end{array}$} & \multirow{2}{*}{$\begin{array}{l}\text { Proportion of New } \\
\text { Objects in Surface } \\
\text { Aux-V-O Clauses }\end{array}$} & \multirow[b]{2}{*}{ Gap } \\
\hline total & given & new & total & given & new & given & new & total & & \\
\hline 100 & 50 & 50 & 0 & 0 & 0 & 0 & $0+\left(50^{*} .2\right)=10$ & 10 & $10 / 10=100 \%$ & $100-50=50$ \\
\hline (1) & (2) & (3) & (4) & (5) & (6) & (7) & (8) & (9) & (10) & (11) \\
\hline
\end{tabular}

14. Bies (1996), for instance, estimates these rates as $40 \%$ for new objects and $10 \%$ for given objects in Early New High German. 
number and proportion of underlying OV clauses falls, the proportion of new objects in pre-verbal position (column 10) and the gap (column 11) between this proportion and the proportion of new objects in the language remains exactly the same. It suddenly becomes undefined when there are no longer any underlying Aux-O-V clauses in the language. This is as expected: although the number of underlying OV clauses decreases, the object in these clauses is always base-generated in pre-verbal position, and the process affecting them (postposition of new objects in narrow focus) continues to function at a constant rate $(20 \%$ by assumption $b)$. Change occurs only when the frequency of underlying OV structure falls to $0 \%$.

Turning now to the pre-verbal field in VAux clauses, the model shown in Table 5 below gives the same results as the AuxV model for pre-verbal new objects and the VAux model for postverbal given objects: the proportion of new objects in preverbal position (column 10) in surface Aux-O-V clauses and the overall proportion of new objects in the language remain constant at $44 \%$ and $50 \%$ respectively. This means that the gap remains constant, thus exactly matching the first row in Table 4 which represents the point before the change from OV to VO begins. There can be no change over time with respect to the proportion of OV/VO in VAux clauses: although their number decreases, the object is always base-generated in pre-verbal position, and all of the objects in postverbal position are in narrow focus.

Table 4. A model of the interaction of syntactic change and information status over time in AuxV clauses, with respect to new objects in the pre-verbal field

\begin{tabular}{|c|c|c|c|c|c|c|c|c|c|c|}
\hline \multicolumn{3}{|c|}{$\begin{array}{l}\text { Underlying OV } \\
\text { Structure }\end{array}$} & \multicolumn{3}{|c|}{$\begin{array}{l}\text { Underlying Vo } \\
\text { Structure }\end{array}$} & \multicolumn{3}{|c|}{$\begin{array}{c}\text { Surface } \\
\text { Aux-O-V Order }\end{array}$} & \multirow{2}{*}{$\begin{array}{l}\text { Proportion of New } \\
\text { Objects in Surface } \\
\text { Aux-O-V Clauses }\end{array}$} & \multirow[b]{2}{*}{ Gap } \\
\hline total & given & new & total & given & new & given & new & total & & \\
\hline 100 & 50 & 50 & 0 & 0 & 0 & 50 & $50-\left(50^{*} .2\right)=40$ & 90 & $40 / 90=44 \%$ & $44-50=-6$ \\
\hline 80 & 40 & 40 & 20 & 10 & 10 & 40 & $40-\left(40^{\star} .2\right)=32$ & 72 & $32 / 72=44 \%$ & $44-50=-6$ \\
\hline 60 & 30 & 30 & 40 & 20 & 20 & 30 & $30-\left(30^{\star} .2\right)=24$ & 54 & $24 / 54=44 \%$ & $44-50=-6$ \\
\hline 40 & 20 & 20 & 60 & 30 & 30 & 20 & $20-\left(20^{\star} \cdot 2\right)=16$ & 36 & $16 / 36=44 \%$ & $44-50=-6$ \\
\hline 20 & 10 & 10 & 80 & 40 & 40 & 10 & $10-\left(10^{*} .2\right)=8$ & 18 & $8 / 18=44 \%$ & $44-50=-6$ \\
\hline 0 & 0 & 0 & 100 & 50 & 50 & 0 & $0-\left(0^{\star} .2\right)=0$ & 0 & - & - \\
\hline$(1)$ & (2) & (3) & (4) & (5) & (6) & (7) & (8) & (9) & (10) & (11) \\
\hline
\end{tabular}

Table 5. A model of the interaction of syntactic change and information status over time in VAux clauses, with respect to new objects in the pre-verbal field

\begin{tabular}{|c|c|c|c|c|c|c|c|c|c|c|}
\hline \multicolumn{3}{|c|}{$\begin{array}{l}\text { Underlying OV } \\
\text { Structure }\end{array}$} & \multicolumn{3}{|c|}{$\begin{array}{l}\text { Underlying VO } \\
\text { Structure }\end{array}$} & \multicolumn{3}{|c|}{ Surface O-V-Aux Order } & \multirow{2}{*}{$\begin{array}{l}\text { Proportion of New } \\
\text { Objects in Surface } \\
\text { O-V-Aux Clauses }\end{array}$} & \multirow[b]{2}{*}{ Gap } \\
\hline total & given & new & total & given & new & given & new & total & & \\
\hline 100 & 50 & 50 & 0 & 0 & 0 & 50 & $50-\left(50^{\star} \cdot 2\right)=40$ & 90 & $40 / 90=44 \%$ & $44-50=-6$ \\
\hline (1) & (2) & (3) & (4) & (5) & (6) & (7) & (8) & (9) & (10) & (11) \\
\hline
\end{tabular}


To summarize, we have used a syntactic model in which there are two distinct post-verbal positions for objects in AuxV clauses: one for narrow focus objects (structure (16)) and one for nonfocused objects (structure (15)). We assume that the frequency of structure (15) increases over time, at the expense of AuxV clauses with pre-verbal objects (structure (14)). These assumptions enable us to make empirical predictions and formulate three hypotheses, which are tested in Section 5:

- Hypothesis 1: in AuxV clauses, the gap between the proportion of new objects in the postverbal field and the proportion of new objects in the AuxV clauses of the language will decrease and approach zero over time (Table 2).

- Hypothesis 2: in contrast, the gap between the proportion of new objects in the pre-verbal field of AuxV clauses and the proportion of new objects in the AuxV clauses of the language will remain constant (Table 4).

- Hypothesis 3: in both the pre-verbal and the post-verbal fields of VAux clauses, the gap will remain constant over time (Tables 3 and 5): VAux clauses are not affected by the change from $\mathrm{OV}$ to $\mathrm{VO}$, and therefore the position of objects is determined solely by information status.

\section{Testing the models}

In order to use the OE and ME data to test the models we created, we need a scale on which we can rank texts, e.g. the date of composition, so that we can see the progression of the OV to VO change over time. Unfortunately, OE texts are generally difficult to date accurately; and due to factors such as standardisation, register, genre, authorial and scribal practice, the date of a text, even when known, does not always reflect its true position in the trajectory of change. We could make the assumption that early texts have low frequencies of underlying VO structure and later texts have higher frequencies and use the rate of underlying structure as a scale, but two problems arise. The first is methodological: making the assumption of a scale based on underlying structure is circular reasoning, since we are trying to demonstrate that the frequency of VO structure increases over time. The second problem is practical: as discussed above, for any given clause with AuxVO surface word order, there is no direct way to determine whether the underlying structure is $(15)(=\mathrm{VO})$ or $(16)(=\mathrm{OV})$; so it is impossible to calculate the frequencies of the two structures. Nevertheless, in order to test the models we created, we need a scale on which we can rank texts as more or less innovative. Since verb order is also changing over this period, with AuxV order gradually replacing VAux order, we use the proportion of AuxV clauses ${ }^{15,16}$

15. We use the proportion in subordinate clauses only. In some main clauses there is ambiguity in the landing site of the finite auxiliary verb, I or $\mathrm{C}$; and $\mathrm{V}$ to $\mathrm{C}$ movement masks the underlying position of I (just as $\mathrm{V}$ to I movement of finite main verbs masks the underlying position of $\mathrm{V}$ ).

16. AuxV surface order does not necessarily represent head-initial IP, since verb (projection) raising can derive AuxV orders from head-final IP structure in OE (Pintzuk 1999, Haeberli and Pintzuk 2004). We therefore performed a structural analysis of the AuxV subordinate clauses, i.e. we assigned head-initial structure to clauses with the finite auxiliary in first or second position and to clauses 
in each text as an independent measure of innovativeness, with texts having more AuxV order being ranked as more innovative. ${ }^{17}$ The ranking is shown in Table 6 below, with Orosius ranked 1 as the most conservative text, Ancrene Riwle ranked 10 as the most innovative. While the differences in the frequencies of AuxV order in the middle part of Table 6 are small and not statistically significant,we do see clear and significant differences between the texts at the bottom, middle and top end of the scale.

In order to compare our data to the model, we need the overall proportion of new objects in each text for AuxV and VAux clauses, regardless of whether the objects are in pre- or post-verbal position. In the models we assumed a uniform proportion (50:50) of new vs. given objects, and in general we would expect the proportion to be fairly uniform across texts, although some variation by text is inevitable. Table 7 shows the overall proportion of new objects, with the texts ordered by the rank of Table 6, i.e. from most conservative to most innovative; proportions that are based on small numbers are bracketed. The proportion of new objects in AuxV clauses ranges from $27.3 \%$ in Orosius to $47.4 \%$ in Catholic Homilies II, with an average of $39.0 \%$ over all texts; in VAux clauses, the proportion ranges

Table 6. The frequency of AuxV order in OE and EME subordinate clauses

\begin{tabular}{lrrcc}
\hline Text & AuxV & N & \%AuxV & Rank \\
\hline Orosius & 405 & 929 & 43.6 & 1 \\
Boethius & 539 & 892 & 60.4 & 2 \\
Cura Pastoralis & 1016 & 1565 & 64.9 & 3 \\
Catholic Homilies I & 912 & 1350 & 67.6 & 4 \\
Catholic Homilies II & 759 & 1117 & 67.9 & 5 \\
Lives of Saints & 857 & 1221 & 70.2 & 6 \\
Gregory's Dialogues (C) & 1191 & 1642 & 72.5 & 7 \\
Trinity Homilies & 372 & 438 & 84.9 & 8 \\
Katherine Group & 454 & 509 & 89.2 & 9 \\
Ancrene Riwle & 576 & 588 & 98.0 & 10 \\
\hline
\end{tabular}

with the finite auxiliary in third position with a pronoun before the auxiliary; we assigned headfinal IP structure to clauses with two or more 'heavy' constituents before the finite auxiliary, etc. The ranking from this structural analysis was not significantly different from the ranking in Table 6 based solely on the surface order of the verbs.

17. Another perhaps more convincing method would be to construct a ranking based on a text's progress in a number of different ongoing changes (e.g. the change in verb order, proportion of head-final pronominal PPs, the loss of object clitics) using a technique such as principle components analysis to create the best single ranking based on data from all the changes. We leave this for future research. 
Table 7. The proportion of new objects in main and subordinate clauses in OE and EME texts, by clause type and text

\begin{tabular}{lccccccc}
\hline & \multicolumn{3}{c}{ AuxV Clauses } & & \multicolumn{3}{c}{ VAux Clauses } \\
\cline { 2 - 5 } \cline { 6 - 8 } Text & $\begin{array}{c}\text { New } \\
\text { Objects }\end{array}$ & $\begin{array}{c}\text { Total } \\
\text { Objects }\end{array}$ & $\%$ New & & $\begin{array}{c}\text { New } \\
\text { Objects }\end{array}$ & $\begin{array}{c}\text { Total } \\
\text { Objects }\end{array}$ & $\%$ New \\
\hline Orosius & 30 & 110 & 27.3 & & 19 & 75 & 25.3 \\
Boethius & 65 & 143 & 45.5 & & 11 & 75 & 14.7 \\
Cura Pastoralis & 25 & 62 & 40.3 & & 21 & 58 & 36.2 \\
Catholic Homilies I & 70 & 192 & 36.5 & & 22 & 74 & 29.7 \\
Catholic Homilies II & 36 & 76 & 47.4 & & 17 & 60 & 28.3 \\
Lives of Saints & 28 & 93 & 30.1 & & 10 & 49 & 20.4 \\
Gregory's Dialogues (C) & 21 & 57 & 36.8 & & 11 & 43 & 25.6 \\
Trinity Homilies & 44 & 97 & 45.4 & & 2 & 4 & {$[50.0]$} \\
Katherine Group & 24 & 75 & 32.0 & & 0 & 4 & {$[0.0]$} \\
Ancrene Riwle & 69 & 159 & 43.4 & & 0 & 1 & {$[0.0]$} \\
\hline Total & 412 & 1064 & 38.7 & & 113 & 443 & 25.5 \\
\hline
\end{tabular}

from $14.7 \%$ in Boethius to $36.2 \%$ in Cura Pastoralis. ${ }^{18}$ As expected, there is no particular pattern to the proportion for each text.

Our first hypothesis from Section 3.2 is that in AuxV clauses, the gap between the proportion of new objects in the post-verbal field and the overall proportion of new objects in AuxV clauses decreases and approaches zero over time (compare Table 2); in other words, the gap will be larger in the more conservative texts and smaller in the more innovative texts. In Table 8 below, we see that for the most part the hypothesis is confirmed: it is clear that the size of the gap is decreasing from the conservative to the innovative texts. In the more conservative $\mathrm{OE}$ texts, the gaps range from 15.6 to 9.7; while in the more innovative $\mathrm{OE}$ texts, the gaps are in the range 3.2 to 6.4. Two of the EME texts (Trinity Homilies and Katherine Group) have gaps of less than 1 in absolute value. One unexpected result is the gap of 2.8 for Ancrene Riwle: although it is the most innovative EME text with respect to verb order (see Table 6), the gap is closer to those of the more innovative $\mathrm{OE}$ range. The gaps at this end of the table are very small, however, and the difference between any two adjacent texts is unlikely to be significant; it may be that by the end of the OE period, the gaps are becoming too small to rank accurately for the more innovative texts.

Our second hypothesis from Section 3.2 is that in AuxV clauses, the gap between the proportion of new objects in the pre-verbal field and the overall pro-

18. For each text, the proportion of new objects is higher in AuxV clauses than in VAux clauses. This is possibly because there are more new objects in main clauses, and there are more main clauses with AuxV verb order than with VAux verb order. This difference between AuxV clauses and VAux clauses is the reason that we compare proportions within AuxV clauses and proportions within VAux clauses, but never mix the two. 
portion of new objects in AuxV clauses will remain constant (compare Table 4). In Table 9 below, we see that the hypothesis is confirmed: although there is a great deal of variation in the size of the gap, there is no obvious trend. ${ }^{19}$

Table 8. The proportion of new objects in the post-verbal field of AuxV clauses compared to the proportion of new objects overall in AuxV clauses ${ }^{1}$

\begin{tabular}{lccccc}
\hline Text & New VO & Total VO & \% New VO & \% Total New & Gap \\
\hline Orosius & 9 & 21 & 42.9 & 27.3 & 15.6 \\
Boethius & 40 & 72 & 55.6 & 45.5 & 10.1 \\
Cura Pastoralis & 14 & 28 & 50.0 & 40.3 & 9.7 \\
Catholic Homilies I & 36 & 84 & 42.9 & 36.5 & 6.4 \\
Catholic Homilies II & 17 & 33 & 51.5 & 47.4 & 4.1 \\
Lives of Saints & 17 & 51 & 33.3 & 30.1 & 3.2 \\
Gregory's Dialogues (C) & 14 & 34 & 41.2 & 36.8 & 4.4 \\
Trinity Homilies & 21 & 46 & 45.7 & 45.4 & 0.3 \\
Katherine Group & 15 & 47 & 31.9 & 32.0 & -0.1 \\
Ancrene Riwle & 54 & 117 & 46.2 & 43.4 & 2.8 \\
\hline Column from Table 2 model & $(8)$ & $(9)$ & $(10)$ & & $(11)$ \\
\hline
\end{tabular}

1. OV and VO in Tables 8 and 9 refer to the post-verbal and pre-verbal fields in the surface word order, not underlying structure.

Table 9. The proportion of new objects in the pre-verbal field of AuxV clauses, compared to the proportion of new objects overall in AuxV clauses

\begin{tabular}{lccccc}
\hline Text & New VO & Total VO & \% New VO & \% Total New & Gap \\
\hline Orosius & 21 & 89 & 23.6 & 27.3 & -3.7 \\
Boethius & 25 & 71 & 35.2 & 45.5 & -10.3 \\
Cura Pastoralis & 11 & 34 & 32.4 & 40.3 & -7.9 \\
Catholic Homilies I & 34 & 108 & 31.5 & 36.5 & -5.0 \\
Catholic Homilies II & 19 & 43 & 44.2 & 47.4 & -3.2 \\
Lives of Saints & 11 & 42 & 26.2 & 30.1 & -3.9 \\
Gregory's Dialogues (C) & 7 & 23 & 30.4 & 36.8 & -6.4 \\
Trinity Homilies & 23 & 51 & 45.1 & 45.4 & -0.3 \\
Katherine Group & 9 & 28 & 32.1 & 32.0 & 0.1 \\
Ancrene Riwle & 15 & 42 & 35.7 & 43.4 & -7.7 \\
\hline Column from Table 4 model & $(8)$ & $(9)$ & $(10)$ & & $(11)$ \\
\hline
\end{tabular}

19. This is the normal pattern for relatively small datasets: a large amount of variation with no perceptible trend. We will see in our discussion of Older Icelandic in Section 6 that for a larger dataset, with texts grouped together so that individual author variation is masked, the gaps are more clearly the same, again with no apparent increasing or decreasing trend. 
Our third hypothesis states that for both the pre-verbal and the post-verbal fields of VAux clauses, the gap between the proportion of new objects in the field and the overall proportion of new objects in the VAux clauses of the text will remain constant (Tables 3 and 5) regardless of where the text ranks on the conservative/ innovative scale. This follows from the assumptions that in these clauses, all objects are base-generated pre-verbally and all post-verbal objects are focussed, conditions that do not change over time. VAux clauses are not affected by the change from $\mathrm{OV}$ to VO, and therefore the position of objects in both the pre-verbal field and the post-verbal field is mainly determined by narrow focus. Tables 10 and 11 show that this hypothesis is in general confirmed by the data. Once again, there is no clear pattern, although there is a great deal of variation from text to text. Table 10 shows the proportion of new objects in the post-verbal field.The numbers are very small (we have bracketed gaps that are calculated from less than 10 tokens) and therefore somewhat difficult to interpret, but there are no signs of a consistent decrease in the size of the gap. Table 11 shows the proportion of new objects in the pre-verbal field; the numbers here are larger, at least for the OE texts, and support the hypothesis that there is no significant difference between the proportions in conservative texts and innovative texts.

In summary, we have shown that in AuxV clauses, the locus of the change from $\mathrm{OV}$ to $\mathrm{VO}$, as texts become more innovative, the proportion of new objects in post-verbal position approaches the overall proportion of new objects in the text. We interpret this as indicating that in AuxV clauses, the conservative variant with a post-verbal focus position is gradually being replaced by the innovative variant, in which the post-verbal position has no information structure constraints associated with it. This has the effect of increasingly diluting the proportion of new information in post-verbal position in these clauses as the texts become more innovative.

Table 10. The proportion of new objects in the post-verbal field of VAux clauses, compared to the proportion of new objects overall in VAux clauses

\begin{tabular}{lccccc}
\hline Text & New VO & Total VO & \% New VO & \% Total New & Gap \\
\hline Orosius & 3 & 4 & 75.0 & 25.3 & {$[49.7]$} \\
Boethius & 4 & 5 & 80.0 & 14.7 & {$[65.3]$} \\
Cura Pastoralis & 5 & 14 & 35.7 & 36.2 & 0.5 \\
Catholic Homilies I & 8 & 16 & 50.0 & 29.7 & 20.3 \\
Catholic Homilies II & 3 & 9 & 33.3 & 28.3 & 5.0 \\
Lives of Saints & 8 & 25 & 32.0 & 20.4 & 11.6 \\
Gregory's Dialogues (C) & 6 & 15 & 40.0 & 25.6 & 14.4 \\
Trinity Homilies & 2 & 4 & 50.0 & 50.0 & {$[0.0]$} \\
Katherine Group & 0 & 3 & 0.00 & 0.00 & {$[0.0]$} \\
Ancrene Riwle & 0 & 0 & - & - & - \\
\hline Column from Table 4 model & $\mathbf{( 8 )}$ & $\mathbf{( 9 )}$ & $\mathbf{( 1 0 )}$ & & $(11)$ \\
\hline
\end{tabular}


Table 11. The proportion of new objects in the pre-verbal field of VAux clauses, compared to the proportion of new objects overall in VAux clauses

\begin{tabular}{lccccc}
\hline Text & New OV & Total OV & \% New OV & \% Total New & Gap \\
\hline Orosius & 16 & 71 & 22.5 & 25.3 & -2.8 \\
Boethius & 7 & 70 & 10.0 & 14.7 & -4.7 \\
Cura Pastoralis & 16 & 44 & 36.4 & 36.2 & 0.2 \\
Catholic Homilies I & 14 & 58 & 24.1 & 29.7 & -5.6 \\
Catholic Homilies II & 14 & 51 & 27.5 & 28.3 & -0.8 \\
Lives of Saints & 2 & 24 & 8.3 & 20.4 & -12.1 \\
Gregory's Dialogues (C) & 5 & 28 & 17.9 & 25.6 & -7.7 \\
Trinity Homilies & 0 & 0 & - & - & - \\
Katherine Group & 0 & 1 & 0.0 & 0.0 & {$[0.0]$} \\
Ancrene Riwle & 0 & 1 & 0.0 & 0.0 & {$[0.0]$} \\
\hline Column from Table 5 model & $(8)$ & $(9)$ & $(\mathbf{1 0 )}$ & & $(11)$ \\
\hline
\end{tabular}

In VAux clauses, where no change is taking place, the proportion of new objects in post-verbal position shows no such trend.

\section{Older Icelandic}

In this section we contrast our analysis with that recently put forward by Hróarsdóttir 2009 for Older Icelandic. She proposes that the change from OV to VO is the result of changes in discourse strategies; i.e. that there is a gradual increase in the use of the post-verbal focus position over time which eventually leads to a sudden reanalysis. ${ }^{20}$ Her analysis predicts that the proportion of new objects in post-verbal position rises over time, and then, following the reanalysis, falls abruptly to approximately the overall proportion of new objects in the language. In contrast, we propose that discourse strategies remain unchanged, i.e. the same proportion of objects continues to be focussed over the period, and that the rising frequency of $\mathrm{VO}$ order is the result of the increasing proportion of non-focussed VO structures (structure (15)) and concomitant decrease of focussed VO structures (structure (16)) among the surface Aux-V-O orders. Our analysis predicts that the proportion of new objects in post-verbal position falls over time until it converges with the overall proportion of new objects in the language.

It is clear that the OE data shown in Table 8 for AuxV clauses and in Table 10 for VAux clauses do not support the idea of a gradual increase in the use of the post-verbal focus position over time eventually leading to a sudden reanalysis. While the ME data in Table 8 might be interpreted as the point of reanalysis, the

20. Hróarsdóttir follows a long tradition of similar ideas, starting with Lightfoot 1979, that the grammatical reanalysis occurs at the end of a period of increasing frequency and/or type of syntactic processes that derive VO surface word order. 
OE texts show a decreasing rather than an increasing correlation between focus and post-verbal position. Interestingly, despite Hróarsdóttir's claim to the contrary, the Icelandic data shows exactly the same trend. While it is indeed the case that the rate at which new objects occur in post-verbal position increases over time, as she claims, the same is true for given objects; they also appear more frequently in post-verbal position over time (her Table 2, p.76 reproduced as Table 12, with frequencies given as $\% \mathrm{VO}$ rather than $\% \mathrm{OV}) .{ }^{21}$ These results show a similar pattern to the English data given in Table 13. In the Icelandic data, in fact, the rising trend for both new and given objects in post-verbal position shows up much more clearly than in the English, presumably due to the fact that these data are more accurately ranked, the sample is larger, and each data point is based on more than one text, allowing any peculiarities of individual authors to be evened out.

Table 12. Old versus new information in AuxV clauses in Icelandic texts

\begin{tabular}{lllllrrr}
\hline & \multicolumn{3}{c}{ New information } & & \multicolumn{3}{c}{ Old information } \\
\cline { 2 - 5 } \cline { 7 - 8 } Texts & OV & Vo & \%VO & & OV & Vo & $\%$ VO \\
\hline 14th century & 75 & 204 & 73.1 & & 156 & 36 & 18.8 \\
15th century & 48 & 136 & 73.9 & & 110 & 24 & 17.9 \\
16th century & 50 & 132 & 72.5 & & 77 & 17 & 18.1 \\
17th century & 79 & 314 & 79.9 & & 215 & 104 & 32.6 \\
18th century & 20 & 98 & 83.1 & & 39 & 43 & 52.4 \\
19th century & 84 & 1312 & 94.0 & & 261 & 1072 & 80.4 \\
\hline
\end{tabular}

Table 13. The proportion of post-verbal objects in AuxV clauses in OE and ME texts

\begin{tabular}{|c|c|c|c|c|c|c|c|c|}
\hline \multirow[b]{2}{*}{ Text } & \multicolumn{4}{|c|}{ New objects } & \multicolumn{4}{|c|}{ Given objects } \\
\hline & OV & vo & Total & $\%$ Vo & OV & Vo & Total & $\% \mathrm{VO}$ \\
\hline Orosius & 21 & 9 & 30 & 30.0 & 68 & 12 & 80 & 15.0 \\
\hline Boethius & 25 & 40 & 65 & 61.5 & 46 & 32 & 78 & 41.0 \\
\hline Cura Pastoralis & 11 & 14 & 25 & 56.0 & 23 & 14 & 37 & 37.8 \\
\hline Catholic Homilies I & 34 & 36 & 70 & 51.4 & 74 & 48 & 122 & 39.3 \\
\hline Catholic Homilies II & 19 & 17 & 36 & 47.2 & 24 & 16 & 40 & 40.0 \\
\hline Lives of Saints & 11 & 17 & 28 & 60.7 & 31 & 34 & 65 & 52.3 \\
\hline Gregory's Dialogues (C) & 7 & 14 & 21 & 66.7 & 16 & 20 & 36 & 55.6 \\
\hline Trinity Homilies & 23 & 21 & 44 & 47.7 & 28 & 25 & 53 & 47.2 \\
\hline Katherine Group & 9 & 15 & 24 & 62.5 & 19 & 32 & 51 & 62.7 \\
\hline Ancrene Riwle & 15 & 54 & 69 & 78.3 & 27 & 63 & 90 & 70.0 \\
\hline
\end{tabular}

21. Hróarsdóttir's Icelandic database contains only AuxV clauses. Two insignificant errors in the table have been corrected. 
If we reanalyse Hróarsdóttir's data in Table 12 to show the proportion of new objects in post-verbal position as a proportion of all post-verbal objects (as in Table 8 above), we see that, just as in English, the gap between the proportion of new objects in post-verbal position and the overall proportion of new objects in the sample falls over time.

Likewise, in pre-verbal position in Icelandic, just as in English (see Table 9), the proportion of new pre-verbal objects to new objects overall remains steady over time.

Tables 14 and 15 show that in a language closely related to OE undergoing the same change from $\mathrm{OV}$ to $\mathrm{VO}$, the patterns which we predicted and can discern among the noise in the English data are extremely clear, thus confirming our hypotheses in a very strong way.

Table 14. The proportion of new objects in the post-verbal field of AuxV clauses compared to the proportion of new objects overall in AuxV clauses in Icelandic texts

\begin{tabular}{lccccc}
\hline Text & New VO & Total VO & $\%$ New VO & \% Total New & Gap \\
\hline 14th century & 204 & 240 & 85.0 & 59.2 & 25.8 \\
15th century & 136 & 160 & 85.0 & 57.9 & 27.1 \\
16th century & 132 & 149 & 88.6 & 65.9 & 22.7 \\
17th century & 314 & 418 & 75.1 & 55.2 & 19.9 \\
18th century & 98 & 141 & 69.5 & 59.0 & 10.5 \\
19th century & 1312 & 2384 & 55.0 & 51.2 & 3.8 \\
\hline Column from Table 2 model & $\mathbf{( 8 )}$ & $\mathbf{( 9 )}$ & $\mathbf{( 1 0 )}$ & & $(11)$ \\
\hline
\end{tabular}

Table 15. The proportion of new objects in the pre-verbal field of AuxV clauses compared to the proportion of new objects overall in AuxV clauses in Icelandic texts

\begin{tabular}{lccccc}
\hline Text & New OV & Total OV & \% New OV & Total New & Gap \\
\hline 14th century & 75 & 231 & 32.5 & 59.2 & -26.7 \\
15th century & 48 & 158 & 30.4 & 57.9 & -27.5 \\
16th century & 50 & 127 & 39.4 & 65.9 & -26.5 \\
17th century & 79 & 294 & 26.9 & 55.2 & -28.3 \\
18th century & 20 & 59 & 33.9 & 59.0 & -25.1 \\
19th century & 84 & 345 & 24.3 & 51.2 & -26.9 \\
\hline Column from Table 3 model & $(8)$ & $(9)$ & $(10)$ & & $(11)$ \\
\hline
\end{tabular}




\section{Conclusions}

In this article we have investigated the relation between syntactic change and information status on alternations in OE and EME verb-object order, OV vs. VO. We have shown that while the syntax of the OE/EME VP is changing over time in AuxV clauses, such that the frequency of underlying VO order is increasing, this change is not in any way triggered by or related to changes in information structure. Rather, the effects of information structure remain constant over time. We use a model which posits two post-verbal object positions, one associated with underlying head-final VPs (the conservative variant) triggered by focus and one with underlying head-initial VPs (the innovative variant) with no particular information structure constraints attached. We show that as the innovative head-initial VP increases in frequency over time at the expense of the conservative head-final variant, the proportion of new objects in post-verbal position approaches the proportion of new information objects in the text as a whole. We argue this is the result of the high proportion of new objects in post-verbal position in underlying headfinal VPs being increasingly diluted by the lack of any such effect in the innovative head-initial VPs, as this latter type increases over time. In addition, we show that, as predicted by the model, there is no change in the frequency of new objects in pre-verbal position in AuxV clauses over time, nor is there any change in VAux clauses at all, in either pre- or post-verbal position, as these clauses are not affected by the change from OV to VO. Finally we show that the patterns our model predicts show up even more clearly in Icelandic, a related language undergoing the same change from $\mathrm{OV}$ to $\mathrm{VO}$, strongly confirming our hypotheses.

\section{References}

Arnold, Jennifer E.; Losongco, Anthony; Wasow, Thomas; Ginstrom, Ryan (2000). «Heaviness vs. Newness: The Effects of Structural Complexity and Discourse Status on Constituent Ordering». Language 76-1: 28-55.

Bech, Kristin (2001). Word order patterns in Old and Middle English: A syntactic and pragmatic study. Doctoral dissertation, University of Bergen.

Biberauer, Theresa; Holmberg, Anders; Roberts, Ian (2008). «Linearising disharmonic word orders: the Final-over-Final Constraint». Perspectives on Linguistics in the 21st Century (= Proceedings volume from the ICLK conference held in Seoul in January 2007), edited by K.-A. Kim, pp. 301-318.

Biberauer, Theresa; Newton, Glenda; Sheehan, Michelle (2009). «Limiting synchronic and diachronic variation and change: the Final-over-Final Constraint». Language and Linguistics 10 (15): 701-743.

Bies, Ann (1996). Syntax and discourse factors in Early New High German: Evidence for verb-final word order. MA Thesis. University of Pennsylvania.

Birner, Betty (2006). «Inferential relations and noncanonical word order». In: Birner, Betty; Ward, Gregory (eds.). Drawing the boundaries of meaning: Neo-Gricean studies in pragmatics and semantics in honor of Laurence R. Horn. Amsterdam/ Philadelphia: Benjamins, pp. 31-51. 
Du Bois, John W. (1980). «Beyond definiteness: The trace of identity in discourse». In: Chafe, Wallace L. (ed.). The Pear Stories: Cognitive, cultural, and linguistic aspects of narrative production. Norwood, New Jersey: Ablex Publishing Corporation, pp. 203-274.

Gries, Stefan Th. (2003). Multifactorial Analysis in Corpus Linguistics: A Study of Particle Placement. London: Continuum.

Gundel, Jeanette (1988). «Universals of topic-comment structure». In: Hammond, Michael; Moravcsik, Edith, Wirth, Jessica (eds.). Studies in Syntactic Typology. Amsterdam: John Benjamins, pp. 209-239.

Gundel, Jeanette; Hedberg, Nancy; Zacharski, Ron (1993). «Cognitive status and the form of referring expressions in discourse». Language 69-2: 274-307.

Haeberli, Eric; Pintzuk, Susan (2006). Revisiting verb (projection) raising in Old English. York Papers in Linguistics Series 2, Issue 6: 77-94.

Hinterhölzl, Roland (2009). The role of information structure in word order variation and word order change. In: Hinterhölzl, Roland; Petrova, Svetlana (eds.). Information structure and language change: New Approaches to Word Order Variation in Germanic. Berlin: Mouton de Gruyter, pp. 45-66.

Hróarsdóttir, Porbjörg (2009). «OV languages: expressions of cues». In: Hinterhölzl, Roland; Petrova, Svetlana (eds.). Information structure and language change: New Approaches to Word Order Variation in Germanic. Berlin: Mouton de Gruyter, pp. 67-90.

Karttunen, Lauri (1976). «Discourse referents». In: McCawley, J.D. (ed.). Syntax and semantics 7: Notes from the linguistic underground. New York: Academic Press, pp. 363-385.

Kohonen, Vilja (1978). On the development of English word order in religious prose around 1000 and 1200 A.D.: a quantitative study of word order in context. Åbo: Research Institute of the Åbo Akademi Foundation.

Kroch, Anthony S.; Taylor, Ann (2000a). «Verb-Complement Order in Middle English». In: Pintzuk, Susan; Tsoulas, George; Warner, Anthony (eds.). Diachronic Syntax: Models and Mechanisms. Oxford: Oxford University Press, pp. 132-163.

Kroch, Anthony; Taylor, Ann (eds.) (2000b). Penn-Helsinki Parsed Corpus of Middle English, 2nd edition. Philadelphia: Department of Linguistics, University of Pennsylvania.

Lightfoot, David W. (1979). Principles of Diachronic Syntax. London: Cambridge University Press.

Pintzuk, Susan (1999). Phrase Structure in Competition: Variation and Change in Old English Word Order. New York: Garland.

Pintzuk, Susan (2005). Arguments against a universal base: evidence from Old English. ELL 9-1: 115-138.

Pintzuk, Susan; Taylor, Ann (2006). «The loss of OV order in the history of English». In: Kemenade, Ans van; Los, Bettelou (eds.). Blackwell handbook of the history of English. Oxford: Blackwell Publishing, pp. 249-278.

Prince, Ellen (1981). «Toward a taxonomy of given-new information». In: Cole, Peter (ed.). Radical pragmatics. New York: Academic Press, pp. 223-255.

Taylor, Ann; Pintzuk, Susan (2009). Object position and focus in Old English. Paper presented at Studies in the History of the English Language 6, Banff, Canada, April-May 2009. 
Taylor, Ann; Pintzuk, Susan (2010). VO order, clause type and information status in Old English. Paper presented at the 10th Diachronic Generative Syntax Conference, Cambridge, UK, July 2010.

Taylor, Ann; Pintzuk, Susan (to appear). «The Effect of Information Structure on Object Position in the History of English». To appear in: Los, Bettelou; LopezCouso, Maria José; Meurman-Solin, Anneli (eds.). Information Structure and Syntactic Change, (Oxford Studies in the History of English, Vol.1). Oxford: Oxford University Press.

Taylor, Ann; Warner, Anthony; Pintzuk, Susan; Beths, Frank (2003). The York-TorontoHelsinki Parsed Corpus of Old English Prose. University of York.

Taylor, Ann; Wurff, Wim van der (2005). «Special issue on aspects of OV and VO order in the history of English». ELL 9-1: 1-4.

Wallenberg, Joel (2009). Antisymmetry and the Conservation of C-Command: Scrambling and Phrase Structure in Synchronic and Diachronic Perspective. Ph.D. dissertation, University of Pennsylvania.

Wasow, Thomas (2002). Postverbal Behavior. Stanford CA: CSLI Publications.

Wasow, Thomas; Arnold, Jennifer (2003). «Post-verbal constituent ordering in English». In: Rohdenburg, Günter; Mondorf, Britta (eds.). Determinants of Grammatical Variation in English. Berlin. New York: Mouton de Gruyter, pp. 119-154. 